\title{
Right Glomus Jugulare with Bilateral Carotid Body Mirror Image Tumors in a Young Female: A Rare Case of Sporadic Non-Familial Non-Functional Multicentric Head and Neck Glomus Tumor
}

\author{
Rajeev Bansal ${ }^{1 *}$, Vinod Sharma ${ }^{1}$, Achal Sharma ${ }^{1}$ and Mohnish Grover ${ }^{2}$ \\ ${ }^{1}$ Department of Neurosurgery, SMS Medical College and Hospitals, India \\ ${ }^{2}$ Department of ENT, SMS Medical College and Hospitals, India
}

Submission: April 22, 2019; Published: May 15, 2019

*Corresponding author: Rajeev Bansal, Department of Neurosurgery, SMS Medical College and Hospitals Jaipur, Rajasthan, India

\begin{abstract}
Background: Glomus tumors also known as paraganglioma are slow growing usually benign tumors arising from paraganglia cells derived embryologically from neural crest cells. Glomus tumors of head and neck arises from jugular bulb, carotid body, vagus nerve and middle ear cavity. Multicentric paragangliomas are seen in 10\% of sporadic patients while $30-40 \%$ in familial forms. Sporadic non-familial non-functional multicentric head and neck glomus tumors are exceedingly rare.
\end{abstract}

Conclusion: whenever a glomus tumor is diagnosed always search for another one; as glomus tumors can be multicentric in $10 \%$ of sporadic patients while $30-40 \%$ in familial forms.

Keywords: Non familial; Non-functional; Head and neck tumors; Multicentric

\section{Introduction}

Glomus tumors also known as paragangliomas or chemdectomas are slow growing usually benign, highly vascular tumors of neuroendocrine origin. Glomus tumors originates from glomus cells which are neural crest cell derivatives. Glomus tumors constitute $0.03 \%$ of all neoplasms while $0.6 \%$ of neoplasms of head and neck. In head and neck region the four most common paraganglioma originate from jugular bulb, carotid body, vagus nerve. The diagnosis is based on patient's history, otological and neck examination, contrast enhanced CT scan and MRI brain and neck. Digital substraction angiography can be diagnostic and helps in subsequent embolisation. For safe tumor excision, magnetic resonance venography is also important to decide the possible ligation and excision of sigmoid sinus during tumor removal. Serum and urine catecholamine or their metabolites assays are done to assess functional status of tumor.

\section{Case Presentation}

A young female of 22 years age presented with foul smelling right ear discharge for 24 months, right sided conductive hearing loss for 18 months, low pitch tinnitus for 6 months with slight deviation of face to left side on smiling for 6 months. Patient having no symptoms of headache, palpitations, hypertension or tachycardia. No family history of such tumors present. Patient was asymptomatic for carotid body tumors. No stridor, hoarseness of voice or dyspnoea seen. Neck masses were palpable and nontender.

On examination Rinne's test was negative on right side and Weber's test was lateralized to right side which is suggestive of right sided conductive hearing loss. On pure tone audiometry right sided moderate conductive hearing loss was present. Right sided lower motor neuron facial palsy of House and Brackman grade II was detected, no other significant neural deficits were found. MRI temporal bones with gadolinium contrast suggestive of heterogenous well defined mass lesion of size $30 \times 30 \times 30 \mathrm{~mm}$ seen in right jugular bulb extending into the tympanic cavity compressing and displacing carotid canal, medially the lesion is closely abutting transverse ans sigmoid sinus and extending into the petrous pyramid and involving otic capsule with encasement of cochlea, vestibule antrum. Anteroinferiorly the mass is 
involving bony and cartilaginous external auditory canal and closely abutting right temporomandibular joint (Figure 1).

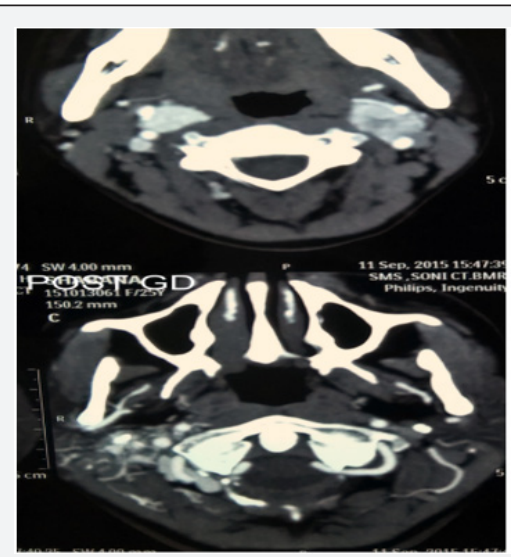

Figure 1: The lesion was intensely enhancing on contrast.

On CT temporal bone with CT angiography two bilateral almost equal sized enhancing mass lesions seen at the bifurcation of common carotid artery measuring right sided $17 \mathrm{~mm}$ and left sided $20 \mathrm{~mm}$ on cerebral CT angiography suggestive of carotid body tumors as seen in (Figure 2). There is a tumor blush with bunch of vessels supplied from external carotid artery seen at the base of skull eroding the right mastoid occupying middle ear cavity extending into external ear cavity eroding jugular foramen occupying the jugular canal suggestive of glomus jugulare tumor. It measures approximately $32 \times 32 \mathrm{~mm}$. No other paraganglioma noted in CT whole abdomen and chest.

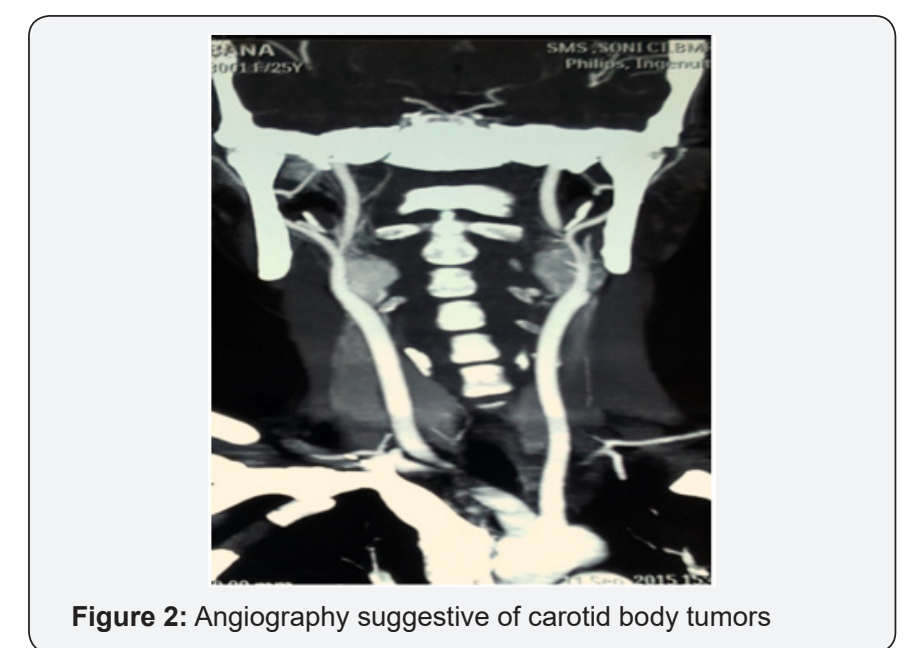

Digital substraction angiography suggestive of bilateral carotid body tumors on internal carotid arteries on both sides. On right external carotid artery injection, marked tumor blush seen in jugular fossa suggestive of glomus jugulare. The tumor was supplied by multiple feeders from right occipital artery, ascending pharyngeal artery and posterior auricular artery. Tumor embolisation was done preoperatively. After two days of embolisation, excision of glomus jugulare tumor done via one stage trans jugular posterior infratemporal fossa approach as shown in Figure 3. On histopathology as seen in Figure 4, nests of cell with antinucleonic separated by vascular fibrous septa seen. Postoperative period was uneventful, and patient discharged with right sided lower motor neuron facial palsy of House and Brackman grade II and right sided hearing loss same as preoperative period.

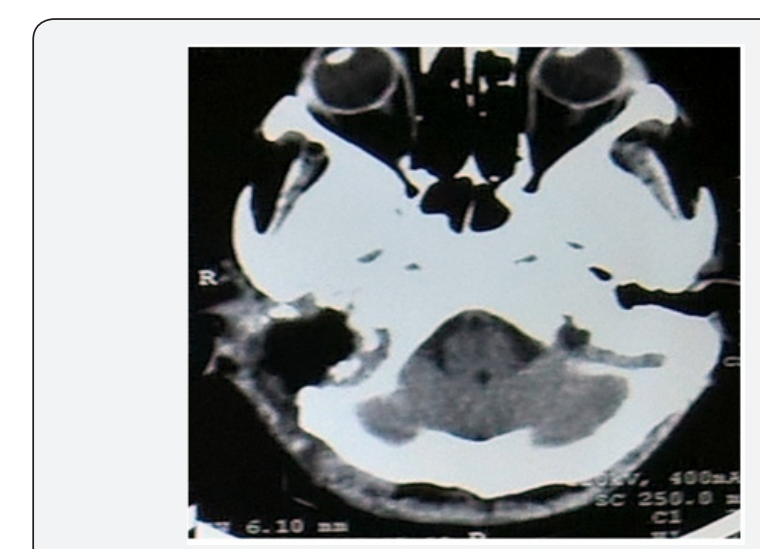

Figure 3: One stage trans jugular posterior infratemporal fossa approach.

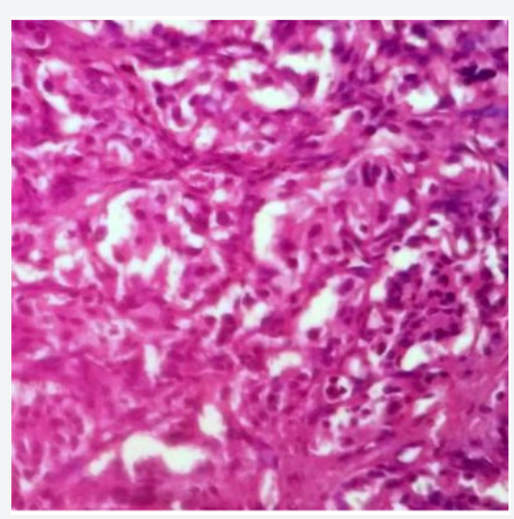

Figure 4: Histopathology.

\section{Discussion}

Glomus tumors constitute $0.03 \%$ of all neoplasms while $0.6 \%$ of neoplasms of head and neck [1,2]. Haller in 1762, described a glomus body like tumors at the carotid bifurcation [3]. Marchand in 1891 reported the first carotid body tumor in medical literature [4]. Mulligan in 1950 introduced the term chemodectoma to describe glomus tumors for their chemoreceptor tissue origin [5]. Glenner and Grimley in 1974 introduced the term paraganglioma to describe glomus tumors.

These tumors may be sporadic or familial. Familial forms can be associated with multiple endocrine neoplasia type-2, neurofibromatosis type-1 and Von Hippel Landau syndrome. Most of the sporadic tumors are solitary while bilateral or multicentric tumors seen in $10 \%$ cases. In familial forms $30-40 \%$ tumors are bilateral or multicentric [2,6]. Maria Agustina Sevilla Garcia et al reported that $11 \%$ glomus tumors are multicentric in study of 89 cases in 73 patients [7]. 
The glomus jugulare tumors are seen in 5th and 6th decade of life with female: male ratio of 6:1 [8]. The carotid body tumors can occur at any age but more commonly seen in 5th decade of life with no gender predilection and uncommon in paediatric population [4]. Hormonally active extra adrenal paraganglioma are functioning tumors. Only $1-3 \%$ of these tumors are functioning and produces symptoms related to catecholamine secretion. These tumors secrete catecholamines several times the normal value but remain subclinical [1-3]. Duke et al reported that glomus tumors can present like pheochromocytoma as they secrete large amounts of norepinephrine. Thus, these tumors can pose hypertensive crisis due to manipulation during surgery [9].

\section{Conclusion}

As in our case patient presented clinically with glomus jugulare but imaging adds two more lesions in carotid bodies bilaterally so whenever a glomus tumor is diagnosed always search for another one; as glomus tumors can be multicentric in $10 \%$ of sporadic patients and $30-40 \%$ in familial forms. Multicentric non-familial, non-functional glomus jugulare with bilateral carotid body tumor is extremely rare association but when a patient with glomus jugulare or tympanicum diagnosed, should be evaluated for its multiple other possible sites at carotid bifurcation, and in abdomen at adrenal glands.

\section{References}

1. Rao AB, Koeller KK, Adair CF (1999) From the archives of the AFIP Paragangliomas of the head and neck: radiologic-pathologic correlation Armed Forces Institute of Pathology. Radiographics 19(6): 1605-1632.

2. Pellitteri PK, Rinaldo A, Myssiorek D, Gary Jackson C, Bradley PJ, et al. (2004) Paragangliomas of the head and neck. Oral Oncol.; 40:563-75.

3. Glenner GG, Grimley PM (1974) Tumors of the extra adrenal paraganglion system (including chemoreceptors). J Clin Pathol 27(9): 766.

4. Lack EE (1997) Tumors of the adrenal gland and extra-adrenal paraganglia. In: Rosaij (ed.) Atlas of tumor pathology, Armed Forces Institute of Pathology, Washington, US, Pp. 303-409.

5. Mulligan RM (1950) Chemodectoma in the dog. Am J Pathol 26: 680681.

6. Wasserman PG, Savargaonkar P (2001) Paragangliomas: Classification, pathology, and differential diagnosis. Otolaryngol Clin North Am 34(5): 845-862.

7. Sevilla García MA, Llorente Pendás JL, Rodrigo Tapia JP, García Rostán G, Suárez Fente V, et al. (2007) Head and Neck Paragangliomas: Revision of 89 Cases in 73 Patients. Acta Otorrinolaringol Esp 58(3): 94-100.

8. Alford B, Guilford F (1962) A comprehensive study of tumors of the glomus jugulare. Laryngoscope 72: 765-787.

9. Duke WW, Boshell BR, Soteres P, Carr JH (1964) A norepinephrinesecreting glomus jugulare tumor presenting as a pheochromocytoma. Ann Intern Med 60: 1040-1047.

\section{Your next submission with Juniper Publishers will reach you the below assets}

- Quality Editorial service

- Swift Peer Review

- Reprints availability

- E-prints Service

- Manuscript Podcast for convenient understanding

- Global attainment for your research

- Manuscript accessibility in different formats

( Pdf, E-pub, Full Text, Audio)

- Unceasing customer service

Track the below URL for one-step submission https://juniperpublishers.com/online-submission.php 